This PDF is a selection from a published volume from the National Bureau of Economic Research

Volume Title: International Dimensions of Monetary Policy

Volume Author/Editor: Jordi Gali and Mark J. Gertler, editors

Volume Publisher: University of Chicago Press

Volume ISBN: 0-226-27886-7

Volume URL: http://www.nber.org/books/gert07-1

Conference Date: June 11-13, 2007

Publication Date: February 2010

Chapter Title: The Effects of Globalization on Inflation, Liquidity and Monetary Policy

Chapter Author: Lucas Papademos

Chapter URL: http://www.nber.org/chapters/c0531

Chapter pages in book: (593 - 608) 


\title{
The Effects of Globalization \\ on Inflation, Liquidity, and Monetary Policy
}

\author{
Lucas Papademos
}

\subsection{Introduction}

My chapter focuses on the effects of globalization on inflation, liquidity, and monetary policy. This subject has received increasing attention among academic economists and policymakers over the past two years. Indeed, a number of distinguished participants in this conference have contributed to the ongoing analysis and public debate on this topic. I have observed, however, that relatively less emphasis has been given so far to the impact of globalization on liquidity and the related implications for monetary policy and financial stability. For this reason, I will also devote some time to these aspects.

It might be interesting to recall that a number of pertinent issues, which I will also address, were already very topical more than 400 years ago, in sixteenth-century Spain. As a consequence of what, undoubtedly, was one of the first and most impressive periods of globalization-benefiting Catalonia, however, only 200 years later ${ }^{1}$ — significant effects on inflation were observed. Of course, I refer to the Spanish discovery of the Americas and the large influx of gold and silver from the New World. The resulting rise in inflation in Spain quickly spread to Western Europe as a whole. ${ }^{2}$ One is thus tempted to talk about the first evidence of global excess liquidity driving global inflation trends. Economic historians have labeled that

Lucas Papademos is Vice-President of the European Central Bank.

1. In 1778, Catalonia was allowed to trade with the Americas by decree of Charles III.

2. Adam Smith estimated that "the discovery of the abundant mines of America reduced, in the sixteenth century, the value of gold and silver in Europe to about a third of what it had been before." See Smith (1776). 
inflationary period a "price revolution." ${ }^{3}$ Then, as now, there was academic debate, beginning as early as the sixteenth century, on whether inflation was due to excess liquidity or rather diminishing domestic economic slack linked to urbanization and income growth. ${ }^{4}$ And, I am sure, it was no coincidence that the quantity theory of money was invented by scholars of the School of Salamanca, who were inspired by the price revolution period in sixteenthcentury Spain. ${ }^{5}$

Even the potential links between globalization, the flattening of the Phillips-curve, and the growing importance of global economic slack were issues already debated at that time. Historians tell us that urbanization also contributed to increased trade between Europe's regions, which made prices more responsive to distant changes in demand. Another topical issue I will elaborate on - the link between global excess liquidity and financial stability - also has its roots in sixteenth-century Spain. Rising inflation and the dependency on gold and silver imports are mentioned as causes of multiple bankruptcies and economic crashes. ${ }^{6}$

Following the agenda set by the sixteenth-century globalization episode, this chapter is divided into two main parts. The first part deals with the effects of globalization on inflation dynamics and price stability from a monetary policy perspective. I will elaborate on the likely impact on product and labor markets as well as the impact on monetary aggregates and financial markets. In the second part, I will reflect on the link between globalization and financial stability, again focusing on the role of central banks. In this context, I will point to the risks associated with global imbalances and asset price boom and bust cycles. I will conclude by addressing two pertinent questions: namely, (a) whether central banks need to adapt their monetary policy strategies in order to cope with the challenges of globalization; and (b) whether monetary policy has become less effective as a consequence of globalization.

As I have already mentioned the term globalization a number of times, and many more references will follow, let me briefly define it in fairly broad terms: it is the process of rapidly increasing global economic integration. Over the past decade, this process involved, and is evidenced by, the unprecedented and pervasive growth in the cross-border trade of goods and services as well as of financial and real assets, but it also involved the swift transfer of technologies, information, and ideas.

3. Hamilton (1934), 186-94, 195-210.

4. Bernholz and Kugler (2007).

5. Navarro, one of the most famous scholars of the School of Salamanca, wrote in 1566 that "Other things being equal, in countries where there is a great scarcity of money, all other saleable goods, and even the hands and labour of men, are given for less money than where it is abundant." Martin de Azpilcueta Navarro, "Comentario Resolutorio de Usuras y Cambios" (Salamanca, 1556).

6. See, for example, Munro (1994). 


\subsection{Globalization, Price Stability, and Monetary Policy}

\subsubsection{Impact of Globalization on Product and Labor Markets}

Let me start by briefly reviewing both the theoretical arguments and the empirical evidence pertaining to the effects of globalization on product and labor markets. It would be too easy to dismiss any inflationary effects stemming from globalization with the argument that its impact will essentially and ultimately result in a change in relative prices and that, ceteris paribus, the overall rate of inflation should not be affected. First, integration is not a one-off event. Steadily rising integration could potentially lead to steadily falling unit labor costs and, ceteris paribus, to protracted periods of lower inflation. Second, a higher degree of openness (and thus increased competition) could lead to permanently higher productivity growth and, again other things being equal, to lower inflation. Third, globalization could affect other aspects of the inflation process and the conduct of monetary policy: the slope of the Phillips-curve, the wedge between the "socially optimal" and the "natural" or "potential" output level, the "natural rate of unemployment" or the non-accelerating inflation rate of unemployment (NAIRU) and even the relative emphasis placed on preserving price stability by the central bank when formulating monetary policy. Thus, globalization could eventually affect the inflationary impact of supply shocks and, more generally, inflation dynamics and the size of the "inflation bias" in the economy.

Many economists and policymakers have examined the effects of globalization on one or several of these factors and processes, partly in order to better understand or explain the recent period of low inflation. Interestingly, sometimes the theoretical arguments and empirical findings point in opposite directions: some have argued that increasing global competition will tend to impinge on domestic monopolistic structures and reduce economic distortions. ${ }^{8}$ Furthermore, the slope of the short-term Phillips curve would increase in the short run as national economies would become more flexible. These two propositions and implied parameter changes in models imply a permanent reduction in the inflation bias. Others have argued instead that the short-term Phillips curve should become flatter. ${ }^{9}$ This reasoning is based on a variety of potential channels: an increased degree of openness reduces the responsiveness of inflation to domestic slack, as profit margins adjust more under increasing competitive pressure and wage setting is

7. "Inflation bias" in this context refers to the component of inflation that results from the implementation of time-inconsistent policies when nominal rigidities create an incentive for policymakers to reduce unemployment by exploiting the short-run trade-off between inflation and unemployment.

8. Rogoff $(2004,2006)$. See Romer (1993) for a similar argument related to openness as a factor that leads to increasing the costs of an inflationary monetary policy due to fears of capital outflows.

9. See, for example, Bean (2006a, 2006b). 
influenced by the threat of outsourcing jobs and labor immigration. There are other factors, however, which potentially could flatten the short-term Phillips curve - the underlying, structural slope or the estimated, effectively observed slope - and that are not necessarily linked to globalization: for example, inflation expectations that are well-anchored to price stability, and less frequent price updates of firms in a low inflation environment.

Alternative or complementary propositions have also been advanced. It has been argued that the whole debate about the slope of the short-term Phillips curve is not particularly relevant, if at all. ${ }^{10}$ In a highly globalized economic environment, lower inflation could simply be due to a decline in the "natural rate of unemployment" or the NAIRU. Importantly, Assaf Razin, among others, has recently shown how the degree of trade and financial integration might both flatten the slope of the short-term Phillips curve and raise the optimal weight to be placed on the central bank's inflation objective, when monetary policy maximizes consumer preferences. ${ }^{11}$ This would lead to the conduct of a more aggressive (optimal) monetary policy in the presence of supply shocks. ${ }^{12}$

Not surprisingly, this debate has triggered a series of empirical studies trying to shed more light on the issue. I will focus on evidence for the euro area. In a recent and often-cited Bank for International Settlements (BIS) paper, Claudio Borio and Andrew Filardo ${ }^{13}$ argue that short-term Phillips curves have become flatter across countries and that measures of global economic slack have become more important than of domestic slack in explaining domestic inflation. Their own results, however, show that this is not the case in the euro area. Moreover, research at the European Central Bank (ECB) does not reveal any statistically significant structural breaks with respect to the slope of the short-term Phillips curve in the euro area or any decline in the estimated value of the slope over time. Other evidence regarding a possible change in the slope of the short-term Phillips curve in the euro area is also very mixed, especially with regard to the potential effect of increased openness on the slope. ${ }^{14}$ The failure to capture econometrically significant globalization effects could, of course, be due to the relatively recent nature of certain aspects of this phenomenon and the impact of other factors that might have had relatively greater influence on inflation dynamics during the past ten years. For this reason, the potential effects of globalization on inflation dynamics, through their influence on behavioral or structural features of the labor and product markets, deserve close monitoring and further analysis.

10. Frankel (2006).

11. Razin and Binyamini (2007).

12. It would also reduce the "inflation bias," as the effect on the bias of a larger weight on the inflation objective dominates that of a flatter Phillips curve in this model.

13. Borio and Filardo (2007).

14. Gnan and Valderrama (2006); Ihrig et al. (2007); IMF (2007); Bean (2005); see also Ciccarelli and Mojon (2005), who find that global factors have greater explanatory power in determining domestic inflation. 
The policy relevance of this debate is further complicated by the fact that even if future empirical studies would confirm a significant drop in the responsiveness of inflation to domestic slack in Phillips curve equations, it is not at all clear whether this should be interpreted as a flattening of the aggregate supply curve in the short term. Such "reduced form" evidence can be observationally equivalent to the evidence that could result from an unchanged structural relationship in an economy where the central bank has been successful in reducing inflation and output volatility, which would correspondingly reduce or could even eliminate the empirical correlation between inflation and the output gap. ${ }^{15}$ For this reason, economists and policymakers have to be particularly careful when using simple reduced form estimated Phillips curve equations to calculate the NAIRU and then employ the estimated value as a benchmark for assessing inflationary pressure.

There are two lessons I derive from this review of theory and evidence. First, there is no consensus at a theoretical level on the relative importance of the various potential effects of globalization on the inflation process through this channel. Second, the available empirical results provide no clear message either, except that, so far, there is not much evidence to support the view that globalization has resulted in a flatter short-term Phillips curve, particularly in the euro area. This situation is, of course, not very comforting for a central banker. The good news is that all studies point toward a lower inflation bias, although for different reasons.

Another related issue is whether, and to what extent, globalization has affected prices and wages more directly in the euro area product and labor markets in the short-to-medium term. Estimates obtained at the Organization for Economic Cooperation and Development (OECD) ${ }^{16}$ employing an accounting framework suggest that the more direct effect of globalization (captured by measures of economic openness) on average annual consumer price inflation is within the range of 0.0 to -0.3 percentage points over the period 2000 to 2005. The average size of the estimated impact is not overwhelming, but at least the upper limit of this range is not negligible either. An internal ECB study finds a comparable negative effect ranging between 0.1 and 0.2 percentage point over the period 1995 to 2004 . The net direct impact of globalization on harmonized index of consumer prices (HICP) inflation is the result of two components: an inflation-dampening effect from noncommodity import prices and an inflation-augmenting effect from commodity import prices, including oil prices. The two effects are, of course, linked and may largely offset each other as the economic success of emerging market economies is largely responsible for higher world commodity prices. Moreover, the interpretation of such estimated effects is not straightforward. The domestic economy's response to the emergence of new international 
low-cost competitors is not captured by these estimates. Furthermore, it is not clear to what extent and for how long these effects should be expected to persist.

The empirical evidence on the direct impact of globalization on labor markets is also mixed. Indeed, it seems that the findings are getting less rather than more robust and it may be difficult to disentangle the effects of globalization from those resulting from technological advances. In theory, it could be expected that the increased openness of economies may affect the demand for labor by firms in advanced economies directly, as a result of intensified international competition and, indirectly, by raising the real wage elasticity of labor demand. There is some evidence confirming these theoretical propositions. ${ }^{17}$ The quadrupling of the effective global labor force over the last twenty years has led to a fall in the labor share of unskilled workers' sectors in advanced economies and to a more moderate rise in the labor share of skilled workers' sectors. In the euro area, shifts in labor demand are predominantly resulting in changes in employment rather than in wages. The International Monetary Fund (IMF) concludes, however, that technological advances had an even bigger impact on the labor share of unskilled workers' sectors than globalization as such.

\subsubsection{Impact on Monetary Aggregates and Financial Markets}

As you are aware, the ECB's monetary policy strategy attributes a prominent role to the analysis of monetary aggregates and their counterparts in the assessment of risks to price stability over the medium to longer run. Two processes associated with globalization have made the analysis of monetary aggregates for the purpose of extracting information for assessing future risks to price stability more complex. ${ }^{18}$

The first process is the growing size of international capital flows. The sum of the stocks of foreign assets and foreign liabilities of the total economy as a percentage of gross domestic product (GDP) - the most frequently used measure of financial globalization - increased threefold in advanced economies between the early 1990s and $2004 .{ }^{19}$ In the euro area alone, the sum of outstanding foreign assets and liabilities increased from 190 percent of GDP in 1999 to 280 percent in $2005 .{ }^{20}$ With larger stocks of foreign assets and liabilities, the probability of occasionally large and volatile net flows has risen. When euro area residents sell securities to non-euro area residents or when they borrow abroad, the net external assets of monetary financial institutions (MFIs) in the euro area rise and the stock of

17. International Monetary Fund (2007).

18. See ECB (2007a, 2007b); Ferrero, Nobili, and Passiglia (2007); von Landesberger (2007).

19. Ferguson et al. (2007).

20. Over the same horizon, the net foreign liability position of the euro area only increased from 6.5 percent to 10 percent of GDP. 
broad money (M3) expands, if the settlement of these transactions involves domestic and foreign banks. Cross-border mergers and acquisitions (M\&A) activity of nonfinancial corporations can also account for a parallel change in net foreign assets and money. Both cross-border portfolio investments and M\&A activity are genuine elements of the process of globalization. Unfortunately, simply accounting for the external sources of money growth and then mechanically correcting for cross-border portfolio flows or M\&A activity, on the presumption of their likely remote direct effects on consumer prices, is not an advisable option. Rather, these transactions have to be analyzed with respect to their information content concerning their potential wealth effects on residents' income and on asset prices. ${ }^{21}$ Depending on the outcome of this analysis, the policy implications could be far from negligible.

The second process is financial innovation. The increasingly global nature of financial markets and the low level of world interest rates in recent years have fostered financial innovation. These developments, in turn, have contributed to the rapid growth of the activities of Other Financial Intermediaries (OFIs), which include investment funds and financial vehicle corporations, as well as dealers in securities and derivative products. While the overall share of OFIs' money holdings in M3 is only about 10 percent in the euro area so far and households hold about 50 percent of the stock of broad money, OFIs have contributed significantly to the annual growth of euro area M3 since 2005, adding up to 2 percentage points in some months, mainly due to the emergence and expansion of loan securitization. The motives of OFIs for holding money balances are likely to be of a fundamentally different nature than those of households or nonfinancial corporations. Moreover, the process of securitization of loans itself positively affects the capacity of banks (of MFIs, to be precise), to issue new loans and thus it could have an indirect expansionary effect on M3 growth. How can we deal with the influence of these factors on money creation and their potential effects on the medium and long-term inflation outlook? In general, the same answer applies with regard to changes in net external assets. Given that the OFIs' money holdings and investment activities could have indirect effects on consumer price developments via asset prices, it would be premature to automatically exclude, without further analysis, the money balances held by OFIs from the monetary aggregates when assessing the risks to price stability. ${ }^{22}$

The general conclusion that emerges from these considerations is that monetary analysis has become more challenging in the global economy as it has to explicitly take account of changes in domestic money and credit markets induced by, or accompanying, financial globalization. To address this challenge, the Eurosystem is currently stepping up its analytical efforts

21. See, for example, the description of the link between M\&A activity and asset prices in Pepper (2006).

22. ECB Monthly Bulletin (2007b). 
to deepen its understanding of several aspects of these processes and their implications for the assessment of medium- to longer-term risks to price stability.

\subsection{Globalization, Financial Stability, and the Role of Central Banks}

A second set of important issues I would like to address concerns the potential effects of globalization on financial stability. The safeguarding of financial stability is an objective embedded, to varying degrees, in central bank statutes, reflecting national or area-wide institutional arrangements. But in all cases, a sufficient degree of financial stability is a necessary condition for the preservation of price stability by central banks. Globalization could have implications for financial stability through various channels. I will focus on its potential implications through its effects on global imbalances and asset price cycles.

\subsubsection{Risks Associated with an Abrupt Unwinding of Global Financial Imbalances}

Incomplete financial globalization, ${ }^{23}$ reflecting the low level of financial market development in otherwise fast-growing emerging market economies, combined with the "savings glut" hypothesis, can partly account for the current level and evolution of global net foreign asset and liability positions. This explanation notwithstanding, the possibility of a disorderly unwinding of global imbalances cannot be excluded for several reasons. First, the structural factors underlying the large financial flows from Asia and oil-exporting countries into the United States cannot persist forever. Second, economic policies that have been causing, or have thus far failed to address, a variety of market distortions and inefficiencies, have also been contributing to existing financial imbalances. Financial market participants may eventually question the sustainability of some of these policies and change their behavior in anticipation of their ultimate consequences. There is no doubt that financial globalization fosters international risk-sharing, promotes economic growth, and reduces macroeconomic volatility. Nevertheless, the size of and the particular asymmetry in net foreign asset positions observed since the late 1990s involves potential medium to longer term risks to financial stability. Major and abrupt asset price adjustments, associated with a disorderly unwinding of global financial imbalances, could be the main propagation mechanism of a financial turbulence. I would like to add, however, that currently the probability of such a disorderly unwinding scenario seems very low, as economic policies are shifting in the right direction, although clearly more needs to be done. Furthermore, as shown by ECB research, historically, the necessary rebalancing of global demand in periods of current account 
adjustment was usually achieved in an orderly fashion and involved domestic demand and supply reallocations and did not require major asset price movements. ${ }^{24}$

The potential role of monetary policy with regard to global imbalances has been examined but the conclusions are not clear. Research at the ECB has shown how the combined effects of domestic monetary policy, fiscal policy, and productivity developments could influence current account positions. ${ }^{25}$ Related exchange rate movements could lead to additional valuation effects with implications for gross foreign asset and liability positions. One interesting question to explore is whether the conduct of symmetric monetary policies - for example, in two countries linked by a fixed exchange rate regime-could affect the relative current account position between these countries. Such an outcome could reflect asymmetries in the interest elasticities of saving and different wealth effects related to heterogeneous financial market development and capitalization. But these issues, though theoretically interesting, are very much unchartered policy territory. ${ }^{26}$

\subsubsection{Impact through Asset Price Boom and Bust Cycles}

Let me now turn to the potential impact of financial globalization on financial stability through the effects on asset prices and risk premia. As colleagues at the BIS were first to emphasize, a potential interaction between globalization and monetary policy may inadvertently contribute to the creation of global excess liquidity, which could later play a role in the development of asset price boom and bust cycles. The benign effects of global competition and low-cost imports on consumer prices might lead to an underestimation of the stimulative effects of monetary policy that is consistent with the preservation of price stability over the medium term, but which can be characterized as accommodative as evidenced by buoyant credit and money growth over a prolonged period. A strong and persistent expansion of monetary liquidity could fuel or even trigger an asset price boom. During the bust phase of the asset price cycle, the associated credit crunch might lead to an economic downturn and a negative deviation from the objective of consumer price stability, and possibly even to deflation, which would exacerbate the financial crisis.

The channel through which monetary liquidity could affect the dynamics of asset prices could be "purely monetarist" or reflect the influence of other factors as more recently explained with reference to behavioral finance. An environment of high monetary liquidity could affect the risk-taking behavior of financial intermediaries and other financial market participants. High

24. Bems and Dedola (2006); Algieri and Bracke (2007); Engler, Fidora, and Thimann (2007); Fratzscher, Juvenal, and Sarno (2007).

25. Bems, Dedola, and Smets (2007).

26. See Dedola (2006) for a discussion of this hypothesis. 
monetary liquidity and financial market liquidity ${ }^{27}$ could be signs of arbitrage strategies such as carry trades and "liquidity seeking" behavior, which could temporarily distort the pricing of risk..$^{28} \mathrm{In}$ fact, ECB research shows that there is evidence that monetary liquidity shocks have played a role in driving asset prices, particularly housing prices across OECD countries, during the boom phase of asset price cycles, and that they have also contributed to explaining the negative effects on economic activity during the subsequent bust phase. ${ }^{29}$ Other Eurosystem research has identified effects of an accommodative monetary policy on housing prices in the euro area and in the United States..$^{30}$ The intriguing aspect of this hypothesis and of the associated empirical findings is that the monetary policy stance might be perfectly appropriate for and consistent with the preservation of price stability over a short-to-medium term horizon. Nevertheless, the potential implications for asset price boom and bust cycles could signal that the monetary policy stance could prove too accommodative for maintaining price stability in the long run.

\subsection{Implications for Policy}

\subsubsection{Do Monetary Policy Strategies Have to Be Adapted?}

I would like to conclude by addressing the two questions that I raised at the beginning that concern the potential implications of globalization for the strategy and effectiveness of monetary policy. More specifically, the first question is whether monetary policy strategies have to be adapted in order to cope with the rapidly increasing global economic integration. In providing an answer, I will concentrate on and highlight the ECB's monetary policy strategy.

A monetary policy strategy comprises two main elements: the policy objective, including the time horizon for its attainment, and the analytical framework, which relates policy instruments and goals and provides the basis for assessing the prospects for attaining the policy objective and the associated risks. The ECB's strategy includes a quantitative definition of its primary objective of preserving price stability and has a medium-term orientation in achieving this goal. Globalization has no fundamental bearing on this element of the strategy, but it has some implications: it does underscore the relative importance of price stability as a central bank goal and the need to formulate and conduct monetary policy so as to preserve price stability

27. See ECB Financial Stability Review (2007a, box 9) for a discussion of the concepts of monetary and financial market liquidity.

28. Rajan $(2005,2006)$.

29. Adalid and Detken (2007); and Detken (2006), with regard to the link between liquidity and low bond yields.

30. Greiber and Setzer (2007). 
over a medium-to-longer term horizon. As I noted earlier, recent research has stressed that increased openness to trade and financial interdependence should reinforce the central bank's emphasis on the objective of price stability relative to minimizing output volatility. ${ }^{31}$ Such a result can also be derived in a model with endogenous portfolio choices, while focusing on the risk-sharing properties of cross-border trade in nominal bonds. ${ }^{32}$ Moreover, in an environment of price stability but persistent rapid money growth and rising leverage, financial liberalization and integration could lead to the accumulation of financial imbalances over a number of years, increasing the probability of a boom and bust cycle in financial markets with repercussions on price stability over the longer term. This possibility implies that monetary policy should place increased emphasis on the preservation of price stability over a longer time horizon, extending beyond the medium term.

With regard to the analytical framework, globalization can, in principle, affect market structures, agent behavior, and inflation dynamics, thus requiring close monitoring and careful assessment of its effects. The economic analysis employed by the ECB to assess the short-to-medium term risks to price stability could be subject to greater parameter or model uncertainty as well as increased measurement error associated with unobservable variables, such as potential output, which underlie the assessment of real activity and inflation pressure. However, the econometric evidence in the euro area has not yet identified significant indirect effects, reflecting structural or behavioral influence of globalization on inflation dynamics. Nevertheless, the complexity of economic analysis has increased and its task has become more challenging, and there is clearly a need to better understand and measure the impact of globalization.

In a period of potentially significant structural change in the product and labor markets, cross-checking the assessment of risks based on economic analysis by monetary analysis becomes more important. This proposition is conceptually correct. Unfortunately, the influences of financial globalization on money and credit growth imply that, in practice, monetary analysis is also becoming more challenging and requires increased sophistication. It is necessary to rely on a wide range of analytical tools and models in order to identify the underlying trend in monetary developments and to assess its implications for price stability. At the same time, as I already stressed, in an environment of increased global financial integration, a deeper and broader analysis of developments in monetary liquidity can enhance our understanding of potential risks to financial stability, which, if they materialize, can have repercussions for output volatility and price stability over the longer term. For these reasons, pertinent research at the ECB will be further strengthened, including the analysis of the interactions between financial

31. Razin and Binyamini (2007).

32. Devereux and Sutherland (2007). 
globalization and innovation on the one hand, and monetary and market liquidity on the other, as well as their potential implications for monetary policy and financial stability.

All in all, there is no reason to change in any fundamental way the analytical framework we employ for assessing the prospects for and the risks to price stability in response to globalization. On the contrary, I conclude that the ECB's strategy, with its medium-to-longer term orientation and the prominence it assigns to the analysis of monetary developments and liquidity conditions for cross-checking the outcome of economic analysis, is well placed to address some of the implications of globalization for inflation dynamics and long-term financial and price stability. Nevertheless, an improved understanding of the influence of globalization on the monetary policy transmission mechanism will enhance the analysis underlying our decisions. This brings me to the second and last question on policy effectiveness.

\subsubsection{Has Monetary Policy Effectiveness Been Reduced?}

Has monetary policy become less effective as a consequence of increased financial integration? More specifically, has the associated comovement of long-term interest rates impaired the functioning of one of the channels of the monetary policy transmission mechanism? Or, alternatively, has monetary policy gained effectiveness in times of almost perfect capital mobility and floating exchange rates, in line with the standard macroeconomic (IS/LM) paradigm, as recently stressed by central bank colleagues? $?^{33}$

Indeed, it is theoretically plausible to argue that certain features of globalization have influenced to varying degrees some of the key determinants of long-term interest rates, such as the global riskless real rate of interest and the real risk premium. ${ }^{34}$ In addition, expected inflation and the inflation risk premium may have been diminished to some degree by forces of globalization, though successful monetary policy across the globe has certainly been the main factor. There is some empirical evidence that in the euro area, as well as in a broader sample of OECD countries, long-term rates are reacting less to changes in short-term rates than they used to. ${ }^{35}$ Global factors seem to be increasingly important for the determination of national real bond yields. ${ }^{36}$ Furthermore, the comovement of U.S., German, and Japanese bond yields has been exceptionally high over the last three years. ${ }^{37} \mathrm{My}$

33. See Yellen (2006) and Weber (2007).

34. Wu (2006). Wu's article is also available at http://www.dallasfed.org; see especially the box "Determining Bond Yields: A Primer."

35. Reichlin (2006).

36. Giannone, Lenza, and Reichlin (2007). Interestingly, already Barro and Sala-i-Martín, in their classic 1990 article, found that real interest rates for seven of the nine OECD countries they investigated mainly depended on world factors for the period 1958 to 1989.

37. Ferguson et al. (2007). 
interpretation of these findings is that, although there is little doubt that global forces have played an important role in the determination of domestic long-term interest rates, they do not provide sufficient and convincing evidence to conclude that the effectiveness of monetary policy in controlling inflation has been reduced. The increased significance of global factors identified by empirical analysis is likely to reflect common trends as well as the similar orientation of monetary policies and their success in containing inflationary pressures. But nothing prevents national monetary policies from diverging from such a common orientation, which itself has been fostered by increasing competition between currencies. ${ }^{38} \mathrm{~A}$ central bank is still able to preserve price stability, or choose and achieve a long-term inflation objective under floating exchange rates. However, the relative importance of the different channels of transmission of the effects of monetary policy might be affected by the ongoing global economic integration. This underscores the importance of the central bank's credible commitment to its objectives and of effective and consistent communication. ${ }^{39}$

\subsection{Concluding Remarks}

To sum up, the effects of globalization on product, labor, and financial markets can be potentially far-reaching. However, the implications for monetary policy are overall fairly contained. The phenomenon of globalization neither calls for any fundamental change in the monetary policy strategy nor does it affect in any material way the general effectiveness of monetary policy. Globalization implies a greater emphasis on the price stability objective over a medium-to longer-term horizon. It also implies that monetary analysis has become more challenging but at the same time relatively more important for assessing long-term risks to price stability and financial stability. Moreover, globalization can affect the relative significance and the functioning of some channels of the monetary policy transmission mechanism, but the available empirical evidence for the euro area suggests that such effects are limited so far. In this context, I would favor the approach of the German writer, philosopher, and engineer Novalis, who mentioned that "hypotheses are like nets; only those who throw nets will catch fish." Clearly, more research is essential. We need close monitoring and careful analysis of the empirical evidence as well as an improved understanding of the influence of globalization on the monetary policy transmission mechanism. This will help improve the quality and robustness of the analysis underlying our ability to continue to fulfill our mandate to maintain price stability and to contribute to the safeguarding of financial stability. 


\section{References}

Adalid, R., and C. Detken. 2007. Liquidity shocks and asset price boom/bust cycles. European Central Bank (ECB) Working Paper Series no. 732.

Algieri, B., and T. Bracke. 2007. Patterns of current account adjustment: Insights from past experience. ECB Working Paper Series no. 762.

Barro, R. J., and X. Sala-i-Martín. 1990. World real interest rates. In NBER Macroeconomics Annual 1990, ed. O. J. Blanchard and S. Fischer, 15-61. Cambridge, MA: MIT Press.

Bean, C. 2005. Monetary policy in an uncertain world. Oxonia Distinguished Speakers Seminar, the Oxford Institute of Economic Policy. 22 February. Oxford, England.

. 2006a. Comments on Kenneth Rogoff: Impact of globalization on monetary policy. Paper presented at the Federal Reserve Bank of Kansas City 30th Annual Economic Symposium. 26 August, Jackson Hole, WY.

2006b. Globalisation and inflation, Speech to the LSE economics society. London School of Economics. 24 October, London.

Bems, R., and L. Dedola. 2006. Current account reversals and capital markets integration: The adjustment of the U.S. external position revisited. ECB Working Paper Series no. 719.

Bems, R., L. Dedola, and F. Smets. 2007. U.S. imbalances: The role of technology and policy. ECB Working Paper no. 719.

Bernholz, P., and P. Kugler. 2007. The price revolution in the 16th century: Empirical results from a structural vectorautoregression model. University of Basle. Working Paper.

Bini Smaghi, L. 2007. Global capital and national monetary policies. Speech at the European Economic and Financial Centre. 18 January, London.

Borio, C., and A. Filardo. 2007. Globalisation and inflation: New cross-country evidence on the global determinants of domestic inflation. Bank for International Settlements (BIS) Working Paper no. 227.

Boivin, J., and M. P. Giannoni. 2006. Has monetary policy become more effective? The Review of Economics and Statistics 88 (3): 445-62.

Ciccarelli, M., and B. Mojon. 2005. Global inflation. ECB Working paper series no. 537.

Dedola, L. 2006. Global imbalances and "excess liquidity": Is there a link? ECB, Directorate General Research, Research Bulletin no. 4.

Detken, C. 2006. Comment on "the bond yield 'conundrum' from a macro-finance perspective." Monetary and Economic Studies 24 (S-1): 109-19. Institute for Monetary and Economic Studies, Bank of Japan.

Devereux, M. B., and A. Sutherland. 2007. Financial globalization and monetary policy. International Macroeconomics, Centre for Economic Policy Research (CEPR) Discussion Paper Series no. 6147.

Engler, P., M. Fidora, and C. Thimann. 2007. External imbalances and the U.S. current account: Do Supply-side changes lessen the exchange rate adjustment? ECB Working Paper Series no. 761.

European Central Bank. 2007a. Financial Stability Review. Frankfurt ECB, December.

European Central Bank. 2007b. Interpreting monetary developments since mid2004. Monthly Bulletin, July.

Ferguson, R., P. Hartmann, F. Panetta, and R. Portes. 2007. International financial stability. Draft Report prepared for the International Center for Monetary and Banking Studies (ICMB) Conference. 3-4 May, Geneva.

Ferrero, G., A. Nobili, and P. Passiglia. 2007. The sectoral distribution of money supply in the euro area. Temi di discussione, Banca d'Italia. 
Frankel, J. 2006. What do economists mean by globalization? Implications for inflation and monetary policy. Written for Academic Consultants Meeting, Board of Governors of the Federal Reserve System.

Fratzscher, M., L. Juvenal, and L. Sarno. 2007. Asset prices, exchange rates and the current account. ECB Working Paper Series no. 790.

Giannone, D., M. Lenza, and L. Reichlin. 2007. The equilibrium level of the world real interest rate. Paper presented at the First Annual Risk Management Institute Research Conference, "Capital Flows and Asset Price: The International Dimension of Risk." 6-7 July, Singapore.

Gnan, E., and M. T. Valderrama. 2006. Globalization, inflation and monetary policy. Monetary Policy and the Economy 4 (January): 37-54.

Greiber, C., and R. Setzer. 2007. Money and housing: Evidence for the euro area and the U.S. Deutsche Bundesbank, Economics Department. Discussion Paper Series 1: Economic Studies, no. 2007, 12.

Hamilton, E. 1934. American treasure and the price revolution in Spain, 1501-1650. Cambridge, MA: Harvard University Press.

Ihrig, J., S. B. Kamin, D. Lindner, and J. Marques. 2007. Some simple tests of the globalization and inflation hypothesis. Board of Governors of the Federal Reserve System, International Finance Discussion Paper no. 891.

International Monetary Fund (IMF). 2007. The globalization of labor, World economic outlook: Spillovers and cycles in the global economy, ed. IMF, 161-92, chapter 5. Washington, DC: IMF.

Kroszner, R. S. 2007. Globalization and capital markets: Implications for inflation and the yield curve. Remarks at the Center for Financial Stability (CEF). 16 May, Buenos Aires, Argentina.

Munro, J. 1994. Patterns of trade, money, and credit. In Handbook of European history 1400-1600: The late Middle Ages, Renaissance and Reformation, ed. J. Tracy, T. Brady, and H. Oberman, 175. Leiden: E. J. Brill.

Pain, N., I. Koske, and M. Sollie. 2006. Globalisation and inflation in the OECD economies. OECD Economics Department Working Papers no. 524.

Papademos, L. 2006. Monetary policy in a changing world: Commitment, strategy and credibility. Speech at the Fourth Conference of the International Research Forum on Monetary Policy. 1 December, Washington, D.C.

Pepper, G., with M. Olivier. 2006. The liquidity theory of asset prices. New York: Wiley Finance.

Rajan, R. 2005. Has financial development made the world riskier? NBER Working Paper no. 11728. Cambridge, MA: National Bureau of Economic Research, November.

2006. Monetary policy and incentives. Paper presented at the Bank of Spain Conference on Central banks in the 21 st century. 8 June, Madrid.

Razin, A., and A. Binyamini. 2007. Flattening of the short-run trade-off between inflation and domestic activity. Paper presented at the Symposium on "The Phillips Curve and the Natural Rate of Unemployment," 3-4 June, Kiel Institute of World Economy.

Reichlin, L. 2006. Panel remarks at the Thirteenth International Conference, "Financial Markets and the Real Economy in a Low Interest Rate Environment." Bank of Japan, 1-2 June, 2006, Tokyo.

Rogoff, K. 2004. Globalization and global disinflation. International Monetary Fund paper prepared for the Federal Reserve Bank of Kansas City Symposium on "Monetary Policy and Uncertainty: Adapting to a Changing Economy." 28-30 August, 2003, Jackson Hole, WY.

. 2006. Impact of globalization on monetary policy. Harvard University paper prepared for the symposium sponsored by the Federal Reserve Bank of Kansas 
City Symposium on "The New Economic Geography: Effects and Policy Implications.” 24-26 August, Jackson Hole, WY.

Romer, D. 1993. Openness and inflation: Theory and evidence. Quarterly Journal of Economics 108 (4): 869-903.

Smith, A. 1776. An inquiry into the nature and causes of the wealth of nations, vol. $X$, the Harvard Classics, ed. C. J. Bullock. New York: P. F. Collier \& Son.

von Landesberger, J. 2007. Sectoral money demand models for the euro area based on a common set of determinants. ECB Working Paper no. 741.

Weber, A. 2007. Challenges posed by (financial) globalisation. Lecture at the University of Pune. 15 March, Pune, India.

Wu, T. 2006. Globalization's effect on interest rates and the yield curve. Economic Letter-Insights from the Federal Reserve Bank of Dallas 1 (9).

Yellen, J. L. 2006. Monetary policy in a global environment. Speech at the Conference on "The Euro and the Dollar in a Globalized Economy," U.C. Santa Cruz. 27 May, University of California Santa Cruz, CA. 